\title{
Karakteristik Kuat Tekan Campuran Beton dengan tambahan Serat Tembaga dan Serbuk Besi
}

\author{
Prabowo Setiyawan ${ }^{1}$, Djoko Susilo Adhy ${ }^{1}$, dan Muhamad Rusli Ahyar ${ }^{\text {* }}$ \\ ${ }^{1}$ Program Studi Teknik Sipil Universitas Islam Sultan Agung, Jl. Kaligawe Raya No.KM, RW.4, Terboyo \\ Kulon, Kec. Genuk, Kota Semarang, Jawa Tengah 50112; \\ ${ }^{*}$ Coresponding author: muhamad.rusli.a@unissula.ac.id
}

\begin{abstract}
waste substances are the result of a production process. If the waste is left without a certain processing, it will polluting and damaging the environment. Some examples of waste that can cause a damage to environment are iron powder and copper fibers. In the development of concrete material technology, many studies have been carried out on the use of waste that can be used as an additive material into concrete mixture. This study aims to determine the effect of adding iron powder and copper fiber waste into concrete mixture based on concrete compressive strength. The concrete compressive strength test is carried out based on the test standard of SNI 03-1974-1990. The test was carried out with a normal concrete of $20 \mathrm{MPa}$ compressive strength. The concrete test specimens are made by giving variations of the addition of iron powder by $2 \%, 2.5 \%$, and $3 \%$ and variations of the addition of copper fiber by $1 \%, 1.5 \%$, and $2 \%$ of the weight of the concrete volume. All specimens were tested when they reached age of 28 days. The test results show that the optimum compressive strength of concrete with the addition of iron powder and copper fiber using a variation of $2 \%$ iron powder and $2 \%$ copper fiber, has a compressive strength of $22.702 \mathrm{MPa}$ with an increase of $0.403 \%$ from normal concrete.
\end{abstract}

Keywords: concrete, compressive strength, iron powder, copper fiber

\begin{abstract}
ABSTRAK
Limbah adalah zat-zat sampah yang merupakan hasil dari suatu proses produksi. Jika limbah dibiarkan tanpa ada suatu proses pengolahan tertentu maka dikhawatirkan akan mencemari lingkungan. Contoh limbah yang dapat merusak lingkungan adalah limbah serbuk besi dan serat-serat tembaga. Dalam perkembangan teknologi material beton, banyak dilakukan penelitian tentang pemanfaatan limbah yang dapat digunakan sebagai bahan campuran beton. Penelitian ini memiliki tujuan untuk mengetahui pengaruh penambahan limbah serbuk besi dan serat tembaga pada campuran beton terhadap kuat tekan beton. Pengujian kuat tekan beton dilakukan berdasarkan standar uji SNI 03-1974-1990. Pengujian dilakukan dengan acuan beton normal dengan mutu rencana $20 \mathrm{MPa}$. Pembuatan sampel benda uji dilakukan dengan cara memberikan variasi penambahan serbuk besi sebesar $2 \%, 2,5 \%$, dan $3 \%$ dan variasi penambahan serat tembaga sebesar $1 \%$, $1,5 \%$, dan $2 \%$ dari berat volume beton. Semua sampel diuji ketika umur beton mencapai 28 hari. Hasil pengujian menunjukkan bahwa kuat tekan optimum beton dengan penambahan serbuk besi dan serat tembaga menggunakan variasi serbuk besi $2 \%$ dan serat tembaga $2 \%$, mempunyai kuat tekan $22,702 \mathrm{MPa}$ dengan kenaikan $0,403 \%$ dari beton normal.
\end{abstract}

Kata kunci : beton, kuat tekan, serbuk besi, serat tembaga

\section{PENDAHULUAN}

Perkembangan pembangunan konstruksi di Indonesia mengalami kemajuan yang sangat pesat. Sebagian besar konstruksi yang ada di Indoneisa dibangun dengan 
menggunakan bahan beton. Bersamaan dengan perkembangan pembangunan konstruksi ternyata diimbangi juga dengan berkembangnya teknologi bahan konstruksi, terutama untuk bahan beton. Perkembangan teknologi beton salah satunya adalah munculnya inovasi mengenai bahan-bahan pengganti campuran beton.

Beton memiliki kelebihan memiliki kuat tekan yang tinggi. Selain itu keunggulan beton terletak pada kemudahan dalam mendapatkan bahan-bahan material campuran beton. Bahan material pembuatan beton secara umum terdiri dari kerikil, pasir, semen, dan air dengan atau tanpa bahan campuran tambahan. (SNI 03-2847-2013).

Dalam perkembangan teknologi material beton, banyak dilakukan penelitian tentang pemanfaatan limbah yang dapat digunakan sebagai bahan campuran beton. Material limbah yang digunakan sebagai bahan tambah dalam campuran beton harus dicari kadar proporsi optimumnya agar bisa mendapatkan kuat tekan beton yang tinggi.

Penelitian oleh Budiyanto, dkk (2015), Susanto, dkk (2015) dam Fasdarsyah (2018) menunjukkan bahwa dengan penambahan serat tembaga pada campuran beton akan menghasilkan benda uji beton dengan kuat tekan dan kuat belah yang lebih tinggi. Selain itu dilakukan penelitian oleh Paryati (2015) dan Purwanto (2020) yang menunjukkan bahwa serbuk besi yang ditambahkan pada campuran beton akan menaikkan kuat tekan beton. Dari dua jenis penelitian tersebut yaitu penambahan serat tembaga pada campuran beton, dan penambahan serbuk besi pada campuran beton, maka penelitian ini bertujuan untuk mengombinasikan kedua gagasan tersebut. Penelitian ini dilakukan dengan tujuan untuk mengetahui pengaruh penambahan serbuk besi dan serat tembaga dalam campuran beton terhadap kuat tekan.

\section{METODE PENELITIAN}

\subsection{Bahan}

Bahan - bahan yang digunakan dalam penelitian ini adalah :

- Semen Portland (PC) tipe I

- Agregat halus berupa pasir muntilan

- Agregat kasar yang digunakan berupa pecahan batu kali dengan ukuran maksimal 20 $\mathrm{mm}$

- Air yang digunakan berasal dari Laboraturium Bahan Konstruksi Fakultas Teknik, Universitas Islam Sultan Agung Semarang 
- Serat tembaga yang digunakan berukuran panjang $10 \mathrm{~cm}$ yang di peroleh dari kabel tipe nyaf dengan ukuran $1,5 \mathrm{~mm}$ dan prosentase proporsi serat tembaga dari berat beton

- Serbuk limbah besi bubut

- Admixture Superplasticizer

\section{2. benda uji}

Pada penelitian beton berserat terdapat beberapa jenis sampel benda uji yang dibuat berdasarkan prosentase campuran serat tembaga dan serbuk besi. Dalam pengujian kuat tekan beton berserat menggunakan silinder dengan ukuran diameter $15 \mathrm{~cm}$ dan tinggi 30 cm. Jumlah sampel benda uji untuk masing - masing pengujian dan kebutuhan material untuk setiap volume $1 \mathrm{~m}^{3}$ dapat dilihat pada tabel 1 dan Tabel 2 di bawah ini :

Tabel 1. Variasi benda Uji yang digunakan

\begin{tabular}{|c|c|c|c|}
\hline \multirow{2}{*}{ Kode Benda Uji } & \multicolumn{2}{|c|}{ Proporsi Campuran } & \multirow{2}{*}{$\begin{array}{c}\text { Jumlah } \\
\text { Benda Uji }\end{array}$} \\
\cline { 2 - 3 } & Serbuk Besi & Serat Tembaga & 3 \\
\hline BB 00 & $0,0 \%$ & $0,0 \%$ & 3 \\
\hline BB A1 & $2,0 \%$ & $1,0 \%$ & 3 \\
\hline BB A2 & $2,0 \%$ & $1,5 \%$ & 3 \\
\hline BB A3 & $2,0 \%$ & $2,0 \%$ & 3 \\
\hline BB B1 & $2,5 \%$ & $1,0 \%$ & 3 \\
\hline BB B2 & $2,5 \%$ & $1,5 \%$ & 3 \\
\hline BB B3 & $2,5 \%$ & $2,0 \%$ & 3 \\
\hline BB C1 & $3,0 \%$ & $1,0 \%$ & 3 \\
\hline BB C2 & $3,0 \%$ & $1,5 \%$ & $2,0 \%$ \\
\hline BB C3 & $3,0 \%$ & & 3 \\
\hline
\end{tabular}

Tabel 2. Kebutuhan Material Tiap Volume $1 \mathrm{~m}^{3}$

\begin{tabular}{|c|c|}
\hline Material & $\begin{array}{c}\text { Kebutuhan Material Tiap Meter Kubik } \\
\left(\mathrm{kg} / \mathrm{m}^{3}\right)\end{array}$ \\
\hline Air & $190 \mathrm{Liter}$ \\
\hline Semen & $316,7 \mathrm{Kg}$ \\
\hline Agregat Halus (Pasir) & $932,8 \mathrm{Kg}$ \\
\hline
\end{tabular}




\begin{tabular}{|c|c|}
\hline Agregat Kasar (Kerikil) & $1010,5 \mathrm{Kg}$ \\
\hline Total & $2450 \mathrm{Kg}$ \\
\hline
\end{tabular}

\subsection{Pengujian Kuat tekan beton}

Kuat tekan beton adalah besar beban per satuan luas. Benda uji beton dibebani dengan gaya tekan tertentu yang dihasilkan oleh mesin tekan hingga hancur. Pengujian kuat tekan beton pada benda uji dilaksanakan pada beton umur 28 hari. Untuk menghitung kuat tekan beton dapat dihitung dengan persamaan 1 berikut:

$$
f \mathrm{c}=\frac{P}{A}
$$

$$
\begin{aligned}
& \text { Keterangan : } \\
& \begin{array}{ll}
f \mathrm{c} & =\text { Kuat tekan beton }(\mathrm{Mpa}) \\
\mathrm{P} & =\text { Beban maksimum }(\mathrm{N}) \\
\mathrm{A} & =\text { Luas bidang tekan }\left(\mathrm{mm}^{2}\right)
\end{array}
\end{aligned}
$$

\section{Hasil dan Pembahasan}

\subsection{Nilai Slump}

Nilai slump merupakan nilai yang diperoleh dari pengujian slump yang diketahui dari penurunan permukaan beton segar untuk mengetahui sifat workability. Semakin besar nilai slump maka beton segar semakin encer, yang berarti semakin mudah pengerjaannya. Nilai slump yang bervariasi dalam setiap hasil pengujiannya disebabkan oleh banyaknya campuran bahan tambah yang digunakan. Nilai slump pada penelitian ini dapat dilihat pada tabel 3 di bawah:

Tabel 3. Nilai Slump pada campuran beton segar

\begin{tabular}{|c|c|c|c|}
\hline Kode Benda Uji & $\begin{array}{c}\text { Persentase } \\
\text { Serbuk Besi }\end{array}$ & $\begin{array}{c}\text { Persentase Serat } \\
\text { Tembaga }\end{array}$ & Nilai Slump $(\mathrm{cm})$ \\
\hline BB 00 & $0,0 \%$ & $0,0 \%$ & 22 \\
\hline BB A1 & $2,0 \%$ & $1,0 \%$ & 18 \\
\hline BB A2 & $2,0 \%$ & $1,5 \%$ & 19 \\
\hline BB A3 & $2,0 \%$ & $2,0 \%$ & 20 \\
\hline BB B1 & $2,5 \%$ & $1,0 \%$ & 17 \\
\hline BB B2 & $2,5 \%$ & $1,5 \%$ & 18 \\
\hline
\end{tabular}




\begin{tabular}{|l|l|l|l|}
\hline BB B3 & $2,5 \%$ & $2,0 \%$ & 19 \\
\hline BB C1 & $3,0 \%$ & $1,0 \%$ & 15 \\
\hline BB C2 & $3,0 \%$ & $1,5 \%$ & 16 \\
\hline BB C3 & $3,0 \%$ & $2,0 \%$ & 17 \\
\hline
\end{tabular}

Dari tabel di atas maka dapat dinyatakan bahwa penambahan proporsi berat serbuk besi dapat menurunkan nilai slump pada campuran beton segar. Sedangkan, penambahan proporsi berat serat tembaga dapat meningkatkan nilai slump pada campuran beton segar. Nilai slump paling kecil ada pada campuran beton dengan proporsi berat serbuk besi $3 \%$ dan proporsi serat tembaga $1 \%$ yaitu sebesar $15 \mathrm{~cm}$.

Penambahan serat tembaga dan serbuk besi memberikan efek menurunkan nilai slump jika dibandingkan dengan nilai slump beton normal. Beton dengan tambahan serat tembaga dan serbuk besi nilai slumpnya mengalami penurunan, maka sifat workability menjadi rendah.

\subsection{Kuat Tekan}

Pengujian kuat tekan dilakukan setelah benda uji berumur 28 hari dengan menggunakan alat compression testing machine. Pengujian ini dilakukan untuk mengetahui kuat tekan maksimum pada setiap beton dengan variasi penambahan serbuk besi dan serat tembaga, setelah diketahui nilai maksimum kuat tekan dimasing - masing benda uji maka dicari nilai kuat tekan dan nilai rata - rata kuat tekan guna mengetahui prosentase penurunan atau peningkatan nilai kuat tekan dari beton dengan penambahan serbuk besi dan serat tembaga dengan nilai kuat tekan beton normal.

Hasil pengujian kuat tekan beton dengan penambahan serbuk besi dan serat tembaga dapat dilihat pada tabel 4 dan gambar 1 dibawah ini :

Tabel 4. Kuat Tekan Beton

\begin{tabular}{|c|c|c|c|c|c|}
\hline \multicolumn{2}{|c|}{ Kode Benda Uji } & $\begin{array}{c}\text { Beban } \\
\text { Maksimum }\end{array}$ & $\begin{array}{c}\text { Kuat Tekan } \\
\text { (MPa) }\end{array}$ & $\begin{array}{l}\text { Kuat Tekan } \\
\text { Rata - Rata }\end{array}$ & $\begin{array}{c}\text { Prosentase } \\
\text { Kenaikan }\end{array}$ \\
\hline \multirow{3}{*}{ Normal } & Normal 1 & 24 & 13,74 & \multirow{3}{*}{19,13} & \multirow{3}{*}{$0 \%$} \\
\hline & Normal 2 & 31 & 17,79 & & \\
\hline & Normal 3 & 46 & 25,87 & & \\
\hline \multirow{3}{*}{ BB A1 } & BB A1.1 & 41 & 23,20 & \multirow{3}{*}{24,90} & \multirow{3}{*}{$30,14 \%$} \\
\hline & BB A1.2 & 50 & 28,30 & & \\
\hline & BB A1.3 & 41 & 23,20 & & \\
\hline \multirow{3}{*}{ BB A2 } & BB A2.1 & 48 & 27,16 & \multirow{3}{*}{26,03} & \multirow{3}{*}{$36,06 \%$} \\
\hline & BB A2.2 & 45 & 25,47 & & \\
\hline & BB A2.3 & 45 & 25,47 & & \\
\hline
\end{tabular}


Vol 26 No 2 Tahun 2021

\begin{tabular}{|c|c|c|c|c|c|}
\hline \multicolumn{2}{|c|}{ Kode Benda Uji } & $\begin{array}{c}\text { Beban } \\
\text { Maksimum }\end{array}$ & $\begin{array}{c}\text { Kuat Tekan } \\
\text { (MPa) }\end{array}$ & $\begin{array}{l}\text { Kuat Tekan } \\
\text { Rata - Rata }\end{array}$ & $\begin{array}{c}\text { Prosentase } \\
\text { Kenaikan }\end{array}$ \\
\hline \multirow{3}{*}{$\mathrm{BB}$ A3 } & BB A3.1 & 47 & 26,60 & \multirow{3}{*}{27,35} & \multirow{3}{*}{$42,96 \%$} \\
\hline & BB A3.2 & 53 & 29,99 & & \\
\hline & BB A3.3 & 45 & 25,47 & & \\
\hline \multirow{3}{*}{ BB B1 } & BB B1.1 & 39 & 22,07 & \multirow{3}{*}{22,45} & \multirow{3}{*}{$17,32 \%$} \\
\hline & BB B1.2 & 44 & 24,90 & & \\
\hline & BB B1.3 & 36 & 20,37 & & \\
\hline \multirow{3}{*}{ BB B2 } & BB B2.1 & 44 & 24,90 & \multirow{3}{*}{24,33} & \multirow{3}{*}{$27,18 \%$} \\
\hline & BB B2.2 & 41 & 23,20 & & \\
\hline & BB B2.3 & 44 & 24,90 & & \\
\hline \multirow{3}{*}{ BB B3 } & BB B3.1 & 49 & 27,73 & \multirow{3}{*}{25,47} & \multirow{3}{*}{$33,10 \%$} \\
\hline & BB B3.2 & 44 & 24,90 & & \\
\hline & BB B3.3 & 42 & 23,77 & & \\
\hline \multirow{3}{*}{$\mathrm{BB} \mathrm{C} 1$} & BB C1.1 & 34 & 19,24 & \multirow{3}{*}{21,13} & \multirow{3}{*}{$10,42 \%$} \\
\hline & BB C1.2 & 40 & 22,64 & & \\
\hline & BB C1.3 & 38 & 21,50 & & \\
\hline \multirow{3}{*}{ BB C2 } & BB C2.1 & 42 & 23,77 & \multirow{3}{*}{21,88} & \multirow{3}{*}{$14,37 \%$} \\
\hline & BB C2.2 & 42 & 23,77 & & \\
\hline & BB C2.3 & 32 & 18,11 & & \\
\hline \multirow{3}{*}{ BB C3 } & BB C3.1 & 44 & 24,90 & \multirow{3}{*}{23,01} & \multirow{3}{*}{$20,28 \%$} \\
\hline & BB C 3.2 & 47 & 26,60 & & \\
\hline & BB C3.3 & 31 & 17,54 & & \\
\hline
\end{tabular}

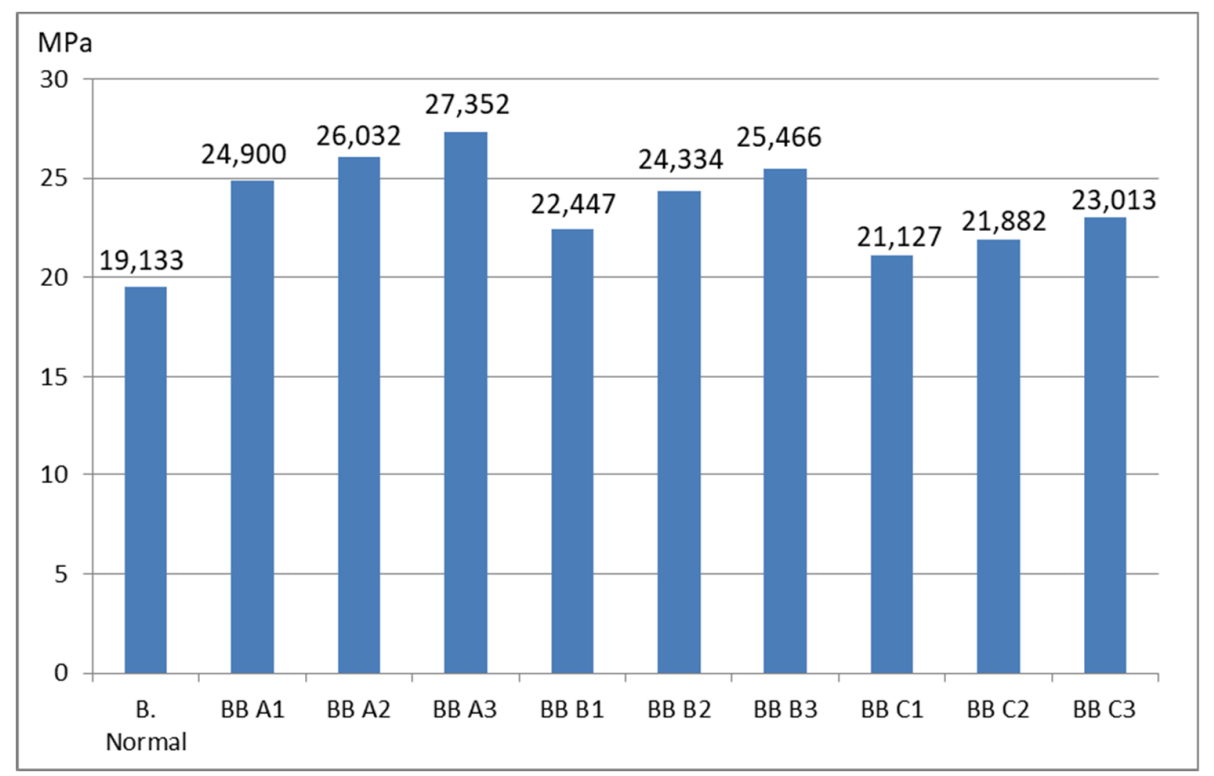

Gambar 1. Diagram Kuat Tekan Beton 
Dari tabel dan gambar di atas dapat dinyatakan bahwa pada beton dengan proporsi berat serbuk besi $(2 \% ; 2,5 \% ; 3 \%)$ maka kuat tekan mengalami penurunan, yaitu 24,9 MPa pada proporsi serbuk besi 2\%, 22,45 MPa pada proporsi serbuk besi 2,5\% dan 21,13 MPa pada proporsi serbuk besi $3 \%$ disetiap proporsi serat tembaga $1 \%$. Begitu halnya dengan proporsi serat tembaga $1,5 \%$ dan $2 \%$.

Proporsi berat serat tembaga yang ditambahkan maka kuat tekannya semakin naik, yaitu 24,9 MPa pada proporsi serat tembaga 1\%, 26,03 MPa pada proporsi serat tembaga $1,5 \%$ dan $27,35 \mathrm{MPa}$ pada proporsi serat tembaga $2 \%$ disetiap proporsi serbuk besi $2 \%$. Begitu halnya dengan proporsi serbuk besi 2,5\% dan 3\%.

Beton dengan penambahan serat tembaga dan serbuk besi salalu mengalami kenaikan kuat tekan dibandingkan dengan beton normal, nilai kuat tekan optimal yaitu 27,35 $\mathrm{MPa}$ dengan proporsi serbuk besi $2 \%$ dan serat tembaga $2 \%$

\section{KESIMPULAN}

Dari hasil penelitian dan pembahasan diatas dapat diambil beberapa kesimpulan sebagai berikut :

- Beton dengan tambahan serat tembaga dan serbuk besi memiliki kuat tekan yang lebih tinggi dibandingkan dengan beton normal. Beton dengan tambahan serat tembaga dan serbuk besi selalu mengalami kenaikan prosentase dari beton normal, kenaikan tertinggi pada $42,96 \%$.

- Kuat tekan tertinggi dari beton dengan tambahan serat tembaga dan serbuk besi terjadi pada BB A3 dengan prosentase serbuk besi $2 \%$ dan serat tembaga $2 \%$, mempunyai kuat tekan 27,35 MPa dengan kenaikan 42,96\% dari beton normal.

\section{DAFTAR PUSTAKA}

Fatima H, W. S. D., \& Murtiningtyas, H. A. (2019). Kuat Tekan Beton dengan Tambahan Serat Tembaga Dan Serbuk Besi (Tugas Akhir: Universitas Islam Sultan Agung).

Budiyanto, R., Prayitno, S., \& Rismunarsi, E. (2015). Pengaruh Penambahan Serat Tembaga Pada Beton Mutu Tinggi Metode Dreux Terhadap Kuat Tekan, Kuat Tarik Belah Dan Modulus Elastisitas. Matriks Teknik Sipil, 3(2).

Susanto, M. E., Prayitno, S., \& Purwanto, P. (2015). Pengaruh Penambahan Serat Tembaga Pada Beton Mutu Tinggi Metode Dreux Terhadap Kuat Tekan, Permeabilitas Dan Penetrasi. Matriks Teknik Sipil, 3(3).

Fasdarsyah, F., \& David, S. (2018). Pengaruh Penambahan Serat Kawat Email Tembaga Pada Campuran Beton Terhadap Kuat Tekan Dan Kuat Tarik Belah. TERAS JURNAL-Jurnal Teknik Sipil, 8(1), 323-328. 
Paryati, N. (2015). Kuat Tekan Beton Dengan Penambahan Serbuk Besi Dan Baja. Bentang: Jurnal Teoritis dan Terapan Bidang Rekayasa Sipil, 3(1), 20-31.

Purwanto, H., \& Wardani, U. C. (2020). Pengaruh Penambahan Serbuk Besi Terhadap Kuat Tekan Beton Mutu K225. Jurnal Deformasi, 5(2), 103-112. 